\title{
Evaluation of neurosurgical implant infection rates and associated pathogens: evidence from 1118 postoperative infections
}

\author{
*Ying Chen, PhD, ${ }^{1}$ Linyan Zhang, MS, ${ }^{1}$ Tingting Qin, MS, ${ }^{2}$ Zhenzhen Wang, MS, ${ }^{1}$ Ying Li, PhD, ${ }^{1}$ and \\ Bing Gu, PhD1,2
}

1Department of Microbiology and Immunology, School of Medical Technology, Xuzhou Medical University; and ${ }^{2}$ Clinical Microbiology Laboratory, Affiliated Hospital of Xuzhou Medical University, Xuzhou, China

\begin{abstract}
OBJECTIVE Various implanted materials are used in neurosurgery; however, there remains a lack of pooled data on infection rates (IRs) and infective bacteria over past decades. The goal of this study was to investigate implant infections in neurosurgical procedures in a longitudinal retrospective study and to evaluate the IRs of neurosurgically implanted materials and the distribution of pathogenic microorganisms.
\end{abstract}

METHODS A systematic literature search was conducted using PubMed and Web of Science databases for the time period between 1968 and 2018. Neurosurgical implant infections were studied in 5 subgroups, including operations or diseases, implanted materials, bacteria, distribution by country, and time periods, which were obtained from the literature and statistically analyzed. In this meta-analysis, statistical heterogeneity across studies was tested by using $p$ values and ${ }^{2}$ values between studies of associated pathogens. Egger's test was used for assessing symmetries of funnel plots with Stata 11.0 software. Methodological quality was assessed to judge the risk of bias according to the Cochrane Handbook. RESULTS A total of 22,971 patients from 227 articles satisfied the study's eligibility criteria. Of these, 1118 cases of infection were reported, and the overall IR was 4.87\%. In this study, the neurosurgical procedures or disorders with the top 3 IRs included craniotomy (IR 6.58\%), cranioplasty (IR 5.89\%), and motor movement disorders (IR 5.43\%). Among 13 implanted materials, the implants with the top 3 IRs included polypropylene-polyester, titanium, and polyetheretherketone (PEEK), which were $8.11 \%, 8.15 \%$, and $7.31 \%$, respectively. Furthermore, the main causative pathogen was Staphylococcus aureus and the countries with the top 3 IRs were Denmark (IR 11.90\%), Korea (IR 10.98\%), and Mexico (IR 9.26\%). Except for the low IR from 1998 to 2007, the overall implant IR after neurosurgical procedures was on the rise.

CONCLUSIONS In this study, the main pathogen in neurosurgery was $S$. aureus, which can provide a certain reference for the clinic. In addition, the IRs of polypropylene-polyester, titanium, and PEEK were higher than other materials, which means that more attention should be paid to them. In short, the total IR was high in neurosurgical implants and should be taken seriously.

https://thejns.org/doi/abs/10.3171/2019.5.FOCUS18582

KEYWORDS neurosurgery; cranioplasty; cerebral surgery; infective bacteria; infection rate

$\mathrm{N}$ EUROSURGERY has many complications including bone resorption, implant exposure, wound dehiscence, delayed hydrocephalus, and infection., ${ }^{2,76}$ Among the various complications, infections associated with neurosurgery can be disastrous, leading to removal of bone or prosthetic flaps, extended hospital stays, and surgical revisions. In recent prospective single-center studies, infection rates (IRs) after cranial neurosurgical procedures varied between $1.6 \%$ and 9\%.13,15,49,82 Recent articles have reported that the overall postoperative IR from cranioplasty is comparatively high, ranging from $3.7 \%$ to $25.6 \% .{ }^{94,95}$

Recent studies regard the success of neurosurgery as dependent on a variety of factors, such as the size and location of neurosurgery procedures, the patient's condition, the implantation time, and the material used. ${ }^{6,37,95}$ The ideal implanted material has the following characteristics: en-

ABBREVIATIONS HA = hydroxyapatite; IR = infection rate; PEEK = polyetheretherketone; $\mathrm{PMMA}=$ polymethylmethacrylate; $\mathrm{SSI}$ = surgical site infection SUBMITTED October 28, 2018. ACCEPTED May 22, 2019.

INCLUDE WHEN CITING DOI: 10.3171/2019.5.FOCUS18582.

${ }^{*}$ Y.C. and L.Z. contributed equally to this work. 
hances aesthetic appearance, is easily affixed to the skull, has low heat conduction, has strong biomechanical processes, and is lightweight, easily shaped, chemically inert, sterilizable, osteoconductive, biocompatible, inexpensive, and readily available. ${ }^{59,71}$ However, the choice of material for neurosurgical practice is still controversial, ${ }^{47,78,90}$ because every material has its own unique set of merits and demerits.

At present, various materials have been used successfully for cranial reconstruction; these include autogenous bone grafts and xenogeneic or alloplastic implants. ${ }^{50,84}$ For example, autologous bone is not subject to immune rejection and is effective as a substrate for bone ingrowth and revascularization. ${ }^{14,53}$ However, there is a risk of resorption, graft infection, longer hospitalization periods, insufficient autogenous grafts, and difficulty in contouring the bone to fit the defects. ${ }^{16,31,73,79,90,94}$ In order to circumvent these problems that exist for autologous bone, several synthetic materials are available for reconstructive surgery. At present, there are primarily 3 types of allografts: metal, ceramic, and polymer. ${ }^{10}$ Titanium as a bone substitute biomaterial is valued for its stability and biocompatibility with a low IR. ${ }^{55}$ However, titanium also has disadvantages-for example, the material is expensive and has a lack of reintegration into the surrounding bone. ${ }^{35,92} \mathrm{Hy}-$ droxyapatite (HA) is a ceramic material that has gained popularity in recent years because of its osteoconductive, non-thermal-conducting features and excellent aesthetic results. ${ }^{8,38,80}$ Unfortunately, HA may be at risk for failure due to risk of hematoma, seroma, infections, and implant exposure. ${ }^{8,80}$ Since the 1940 s, polymethylmethacrylate (PMMA), a polymer, has remained the most widely used material because of its low cost, radiolucency, and stability, and because it is easily moldable and biologically inert. ${ }^{7}$ Nonetheless, its use does come with drawbacks such as infection, fragmentation, and a lack of incorporation. ${ }^{14,35}$

The aim of this meta-analysis was to analyze neurosurgical implant infections and causative bacteria over the past decades. Despite the profusion of reports from different parts of the world regarding implanted materials in neurosurgery, there remains a lack of pooled data on IRs and infective bacteria over the past decades. Herein we have systematically reviewed the literature for all reported data on neurosurgical procedures and other operations associated with infection, implanted materials, infective bacteria, countries in which cases were treated, and time periods.

\section{Methods \\ Search Strategy}

Two independent reviewers (L.Z. and T.Q.) conducted a systematic literature review of potentially qualifying articles and relevant medical journals that reported neurosurgical procedures associated with implant infections. A comprehensive search of the scientific literature was undertaken by querying the electronic databases of PubMed and Web of Science up to April 2018 by using the National Library of Medicine's MeSH terms "neurosurgery" or "cerebral surgery" or "cranioplasty" and "implant infections." The search was not restricted by language, pub- lication status, or geographical distribution of the publications. ${ }^{33}$ If an article was related, then the full text would also be retrieved. When necessary, additional contact was made with the authors of the included articles to ascertain data.

\section{Inclusion and Exclusion Criteria}

The inclusion and exclusion criteria were defined by the researchers prior to the review of literature. The purpose of the search was to discover articles that met the following inclusion criteria: 1) case series reporting the outcome in at least 5 patients; 2) publication date before April 2018; and 3 ) the data regarding implant infections were clear. Exclusion criteria applied to studies were as follows: 1) articles irrelevant to humans; 2) review, case report, or meta-analysis; 3) implanted materials not mentioned and operations irrelevant to neurosurgery; and 4) data unclear and articles duplicative. Furthermore, technical notes, letters, and editorials were excluded.

\section{Validity Assessment}

A systematic review was performed in accordance with PRISMA guidelines. Two separate individuals (L.Z. and T.Q.) independently performed study selection and quality assessment using the Cochrane Handbook, version 5.1.0 (http://handbook-5-1.cochrane.org). The evaluation criteria of each item were judged as "low risk of bias," "unclear risk of bias," and "high risk of bias." If there was any question about the eligibility of an article, data discrepancies were determined through reevaluation by a senior author (B.G.), who could set aside the outcome of the preceding assessment. ${ }^{28}$

\section{Data Extraction and Analysis}

The data extracted from each article included the following: number of patients, operations, and diseases; number of implant materials and infections; IRs; infective bacteria; patient ages; study period; treatment; study subject; country; follow-up; first author; and year of publication. Divergences among any of the above data points were resolved through discussions among the authors. Subgroup analysis was performed to determine the IRs after neurosurgical procedures.

We evaluated the heterogeneity with $\mathrm{I}^{2}$ values according to the Cochrane Handbook. ${ }^{57}$ The fixed-effects model was applied for data synthesis of low heterogeneity $\left(\mathrm{I}^{2}<\right.$ $50 \%$ ), whereas the random-effects model was conducted if the heterogeneity was significant $\left(\mathrm{I}^{2} \geq 50 \%\right)$. If heterogeneity was evaluated as significant $\left(\mathrm{I}^{2} \geq 50 \%\right)$ and the trials included were adequate, we performed a subgroup analysis to explore the potential source of the heterogeneity.

Egger's test was used to assess symmetries of the funnel plot with the aid of Stata 11.0 software. The presence of reporting bias was evaluated by Egger's test when studies included in the review were sufficient ( $>10$ trials). The intercept of the regression line represents the degree of asymmetry deviation. Reporting bias was considered to exist and reliability was considered to be low when the intercept on Egger's graph was far from zero. Conversely, when the intercept on Egger's graph was close to zero, the 


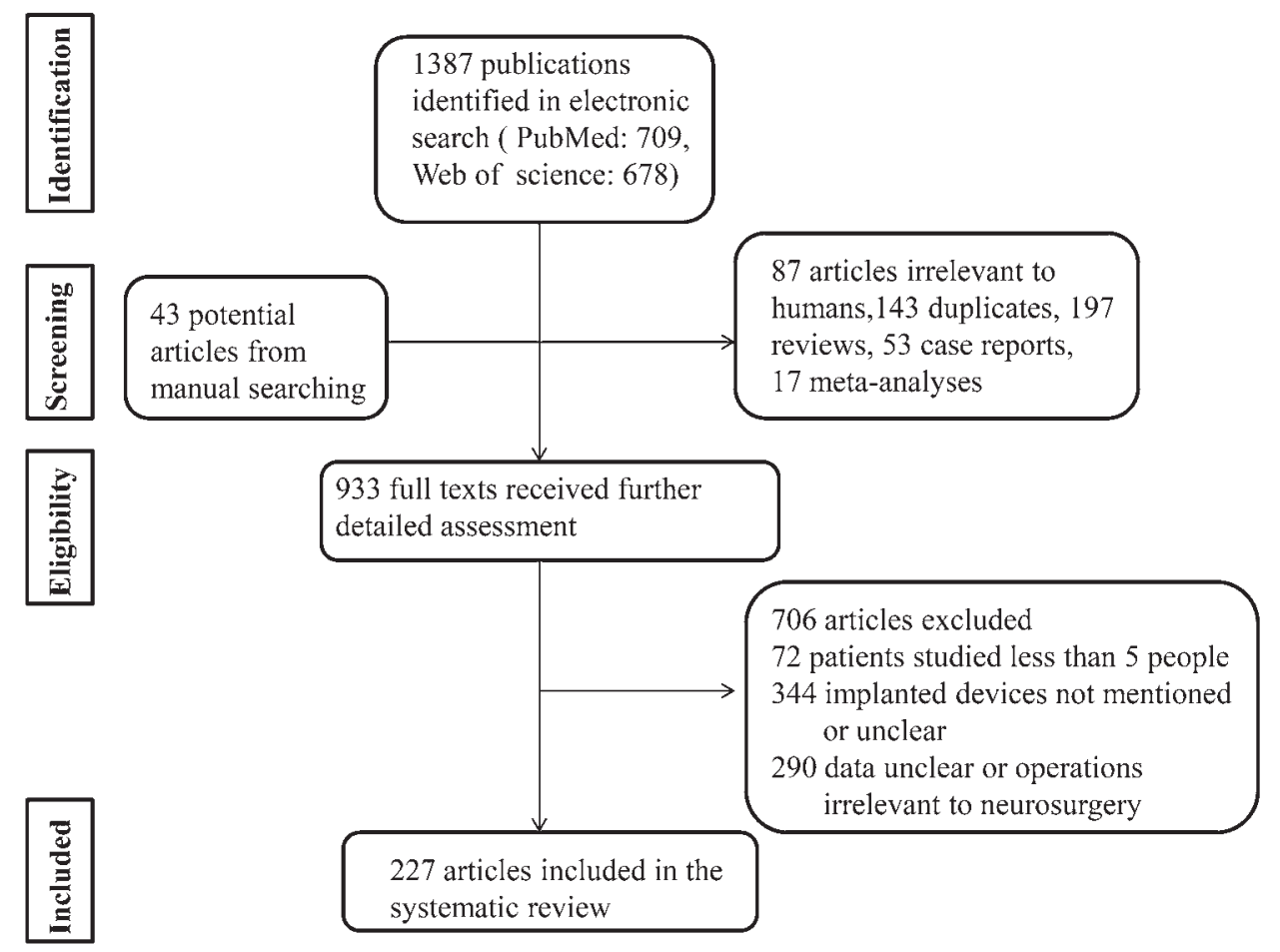

FIG. 1. Flow diagram for selection of studies.

reporting bias was considered to be nonexistent and the result to be reliable.

\section{Results}

\section{Systematic Literature Search}

A total of 1387 articles were identified with the original electronic database search (Fig. 1). A further 43 articles were also identified through manual search, bibliographic search, and reviewer suggestions. After excluding duplicate studies and articles not directly related to our hypothesis, a total of 933 articles remained. Finally, 227 full-text articles were subsequently analyzed based on the inclusion and exclusion criteria established for the review. Systematic review and meta-analysis were performed for 227 studies with a total of 22,971 patients, 1118 cases of infection were reported, and the total IR was $4.87 \%$.

\section{Assessment of Publication Bias}

As can be seen from Egger's publication bias plot (Fig. 2), the intercept of the regression line is close to zero, there is no obvious visual bias, and the result is reliable. In this review, for estimation of publication bias, no statistically significant asymmetry was found according to Egger's test $(\mathrm{t}=-1.60, \mathrm{p}>0.05)$, which means that no significant publication bias was found among studies.

\section{IRs of Operations}

In this study, 9 primarily neurosurgical operations or diseases were counted; some operations were not counted if the number of patients was less than 100. Therefore, a total of 17,632 patients were included, 854 cases of infec- tion were reported, and the overall IR was $4.84 \%$ (Table 1). The most common neurosurgical procedures were cranioplasty, motor movement disorders, and craniosynostosis-among these, 8273 patients underwent cranioplasty. As can be seen from Table 1, the procedures with the top 3 IRs were operations including craniotomy (IR 6.58\%), cranioplasty (IR 5.89\%), and motor movement disorders (IR 5.43\%). In our statistics, motor movement disorders included tremor, spasticity, dystonia, and Parkinson disease; the IR for these disorders was second only to the IRs for cranioplasty and craniotomy, and in recent years these surgeries have also received attention. However, the lower IRs included duraplasty, hydrocephalus, and craniosynostosis, which were $3.17 \%, 2.59 \%, 0.77 \%$, respectively.

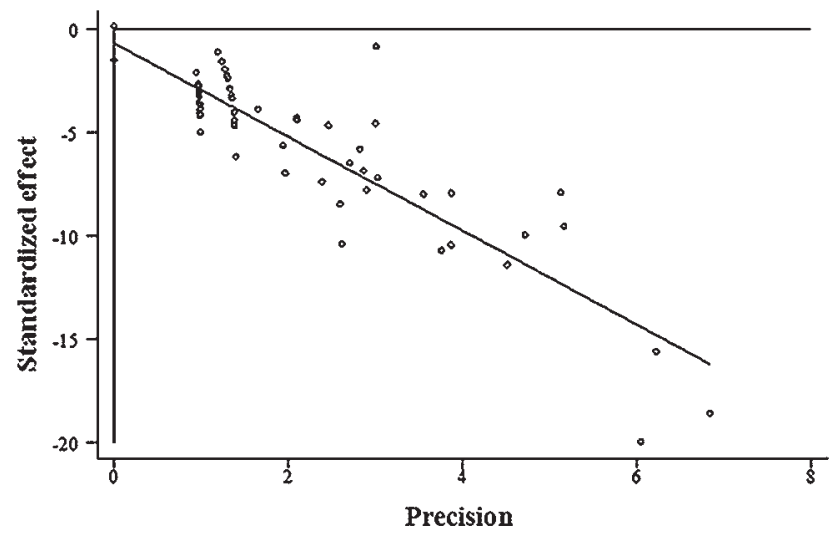

FIG. 2. Egger's publication bias plot of neurosurgical implant infection. 
TABLE 1. IRs of the 9 most common neurosurgical procedures

\begin{tabular}{lrrc}
\hline \multicolumn{1}{c}{ Operation } & Total & No. of Infections & IR $(\%)$ \\
\hline Craniotomy & 1033 & 68 & 6.58 \\
\hline Cranioplasty & 8273 & 487 & 5.89 \\
\hline Motor movement disorders & 3278 & 178 & 5.43 \\
\hline Spinal/brain metastases & 158 & 7 & 4.43 \\
\hline Craniofacial surgery & 707 & 30 & 4.24 \\
\hline Epilepsy & 1185 & 47 & 3.97 \\
\hline Duraplasty & 315 & 10 & 3.17 \\
\hline Hydrocephalus & 348 & 9 & 2.59 \\
\hline Craniosynostosis & 2335 & 18 & 0.77 \\
\hline Total & 17,632 & 854 & 4.84 \\
\hline
\end{tabular}

TABLE 2. IRs of the 13 most common implanted materials

\begin{tabular}{lrrr}
\hline \multicolumn{1}{c}{ Material } & Total & No. of Infections & IR (\%) \\
\hline Implanted pump & 1466 & 138 & 9.41 \\
\hline Titanium implants & 810 & 66 & 8.15 \\
\hline Polypropylene-polyester & 296 & 24 & 8.11 \\
\hline PEEK & 520 & 38 & 7.31 \\
\hline Deep brain stimulation electrodes & 1755 & 115 & 6.55 \\
\hline Autologous bone & 973 & 64 & 6.58 \\
\hline Gliadel wafers & 454 & 26 & 5.73 \\
\hline PMMA & 1223 & 70 & 5.72 \\
\hline Pulse generator & 273 & 11 & 4.03 \\
\hline HA & 694 & 21 & 3.03 \\
\hline Medpor porous polyethylene & 818 & 8 & 0.98 \\
\hline Biodegradable or resorbable & 2897 & 26 & 0.90 \\
$\quad$ devices & & & \\
\hline Dura mater & 172 & 1 & 0.58 \\
\hline Total & 12,351 & 608 & 4.92 \\
\hline
\end{tabular}

\section{IRs of Implanted Materials}

We did a statistical analysis of 13 implanted materials in this meta-analysis, comprising titanium, polypropylene-polyester, PMMA, polyetheretherketone (PEEK), Medpor porous polyethylene, HA, autologous bone, dura mater, Gliadel wafers, deep brain stimulation electrodes, implanted pumps, pulse generators, and biodegradable/ resorbable devices. A total of 12,351 patients were selected, 608 cases of infection were reported, and the overall IR was $4.92 \%$ (Table 2). Of the 13 implanted materials, the IRs of Medpor porous polyethylene, biodegradable or resorbable devices, and dura mater were lowest; these were $0.98 \%, 0.90 \%$, and $0.58 \%$, respectively. The highest 3 IRs were observed with polypropylene-polyester (IR 8.11\%), titanium implants (IR 8.15\%), and PEEK (IR $7.31 \%)$.

\section{Distribution of Pathogenic Microorganisms}

In this meta-analysis, a total of 14 bacterial genera plus anaerobic species were selected, and 34 studies covering
TABLE 3. Distribution of pathogenic microorganisms associated with neurosurgical procedures in 34 studies

\begin{tabular}{|c|c|c|}
\hline Bacteria & Total & $\%$ \\
\hline Staphylococcus spp. & 282 & 76.22 \\
\hline S. aureus & 198 & 53.51 \\
\hline Coagulase-negative Staphylococcus & 74 & 20.00 \\
\hline Unidentified & 10 & 2.70 \\
\hline Streptococcus spp. & 7 & 1.89 \\
\hline$\alpha$-hemolytic streptococci & 1 & 0.27 \\
\hline$\beta$-hemolytic streptococci & 4 & 1.08 \\
\hline Nonhemolytic group D streptococci & 1 & 0.27 \\
\hline Unidentified & 1 & 0.27 \\
\hline Propionibacterium spp. & 27 & 7.30 \\
\hline P. acnes & 20 & 5.41 \\
\hline Unidentified & 7 & 1.89 \\
\hline Klebsiella spp. & 7 & 1.89 \\
\hline K. pneumoniae & 3 & 0.81 \\
\hline K. oxytoca & 3 & 0.81 \\
\hline Unidentified & 1 & 0.27 \\
\hline Escherichia coli & 8 & 2.16 \\
\hline Enterobacter spp. & 14 & 3.78 \\
\hline E. aerogenes & 1 & 0.27 \\
\hline E. cloacae & 4 & 1.08 \\
\hline E. aeruginosa & 6 & 1.62 \\
\hline Unidentified & 3 & 0.81 \\
\hline Serratia marcescens & 3 & 0.81 \\
\hline Proteus mirabilis & 3 & 0.81 \\
\hline Providentia stuartii & 1 & 0.27 \\
\hline Morganella morganii & 1 & 0.27 \\
\hline Pseudomonas spp. & 7 & 1.89 \\
\hline$P$. aeruginosa & 5 & 1.35 \\
\hline Unidentified & 2 & 0.54 \\
\hline Acinetobacter baumannii & 1 & 0.27 \\
\hline Anaerobic spp. & 3 & 0.81 \\
\hline Candida spp. & 6 & 1.62 \\
\hline C. albicans & 1 & 0.27 \\
\hline C. famata & 1 & 0.27 \\
\hline C. parapsilosis & 1 & 0.27 \\
\hline Unidentified & 3 & 0.81 \\
\hline Total & 370 & 100 \\
\hline
\end{tabular}

370 bacterial infection cases were contained in our selected literature (Table 3). The 34 studies describing neurosurgery gave a bacterial distribution estimate of $0.05(95 \%$ CI 0.04-0.07). Statistically significant heterogeneity was observed between studies ( $<<0.001, \mathrm{I}^{2} 83.9 \%$ ) (Fig. 3). In our study population, the predominant pathogenic microorganism isolated was Staphylococcus aureus (53.51\%), which is consistent with other reports, ${ }^{30,43,61,67,72,77}$ followed by coagulase-negative Staphylococcus $(20.00 \%)$ and Propionibacterium acnes $(5.41 \%)$. Therefore, the regimen selected should be aimed at these pathogenic microorganisms. 


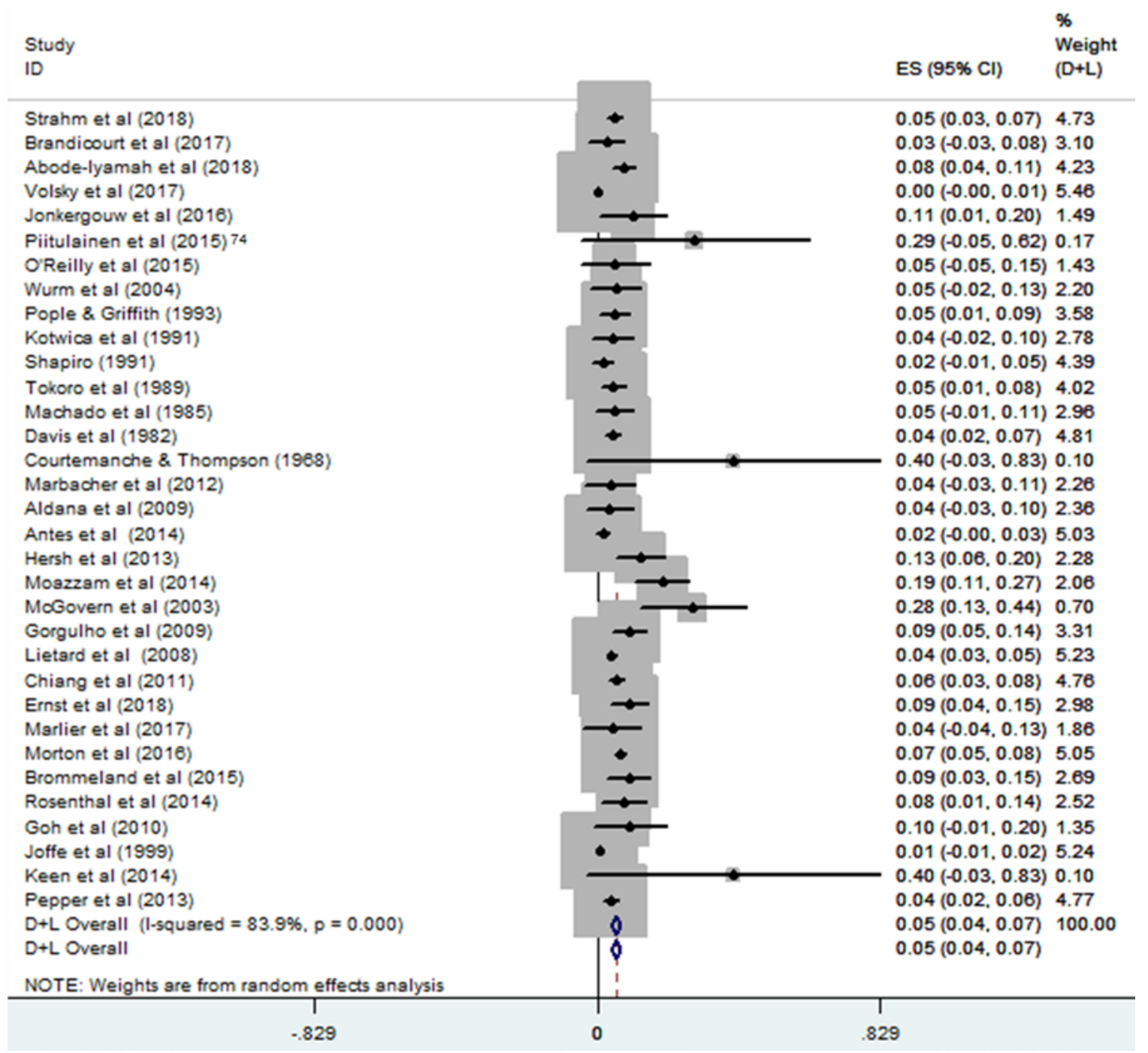

FIG. 3. Forest plot for the meta-analysis of the IR of associated bacteria of neurosurgery (meta-analysis using the random-effects model). The $D+L$ value is the weight that different studies contribute to the combined accuracy ratio. The higher $I^{2}$ values combined with $p$ values $>0.01$ denote greater heterogeneity between those studies. $E S=$ error standard (i.e., standard error).

\section{Distribution of IRs by Country}

Among 227 studies, only 3 articles reported cases by continent; $9,22,26$ therefore, 857 patients were not included. We have calculated that in 22,114 patients from a total of 32 countries in 224 studies, 1050 cases of infection were reported, and the overall IR was $4.75 \%$. Notably, the IRs in Denmark, Korea, and Mexico were high (Fig. 4), which should encourage surgeons in those countries to pay more attention to preventing infections from implants. In China, a total of 540 patients were selected from 16 articles, 26 infections were counted, and the overall IR was $4.81 \%$, which is slightly above the total IR. In addition, a total of 10,869 cases were included from the US in 82 articles, 446 infections were reported, and the overall IR was $4.10 \%$, which is less than the total IR for all studies.

\section{IRs of Time Periods}

The time period was equally divided into 5 time slots, including 1968-1977, 1978-1987, 1988-1997, 1998-2007, and 2008-2018, but because only 1 article was reported in 1968, we only listed 4 time slots. As seen in Table 4, the IR from 2008 to 2018 increased yearly. In the past decades, except for the low IR from 1998 to 2007, the overall implant IRs after neurosurgical procedures have been on the rise, which can provide a certain reference for the clinic.

\section{Discussion}

The development of implant infections in neurosurgery is a significant complication and often requires reoperation, an extended hospital stay, and therapy with antibiotics. To date, cranioplasty is the most common procedure associated with implantation; it can restore cosmesis, provide cerebral protection, facilitate neurological rehabilitation, improve neurological outcome $\mathrm{e}^{36,40,62}$ and provide protection to the underlying brain, and normalize cerebral hemodynamics and metabolism. ${ }^{28,42,52,83}$ Because of these 


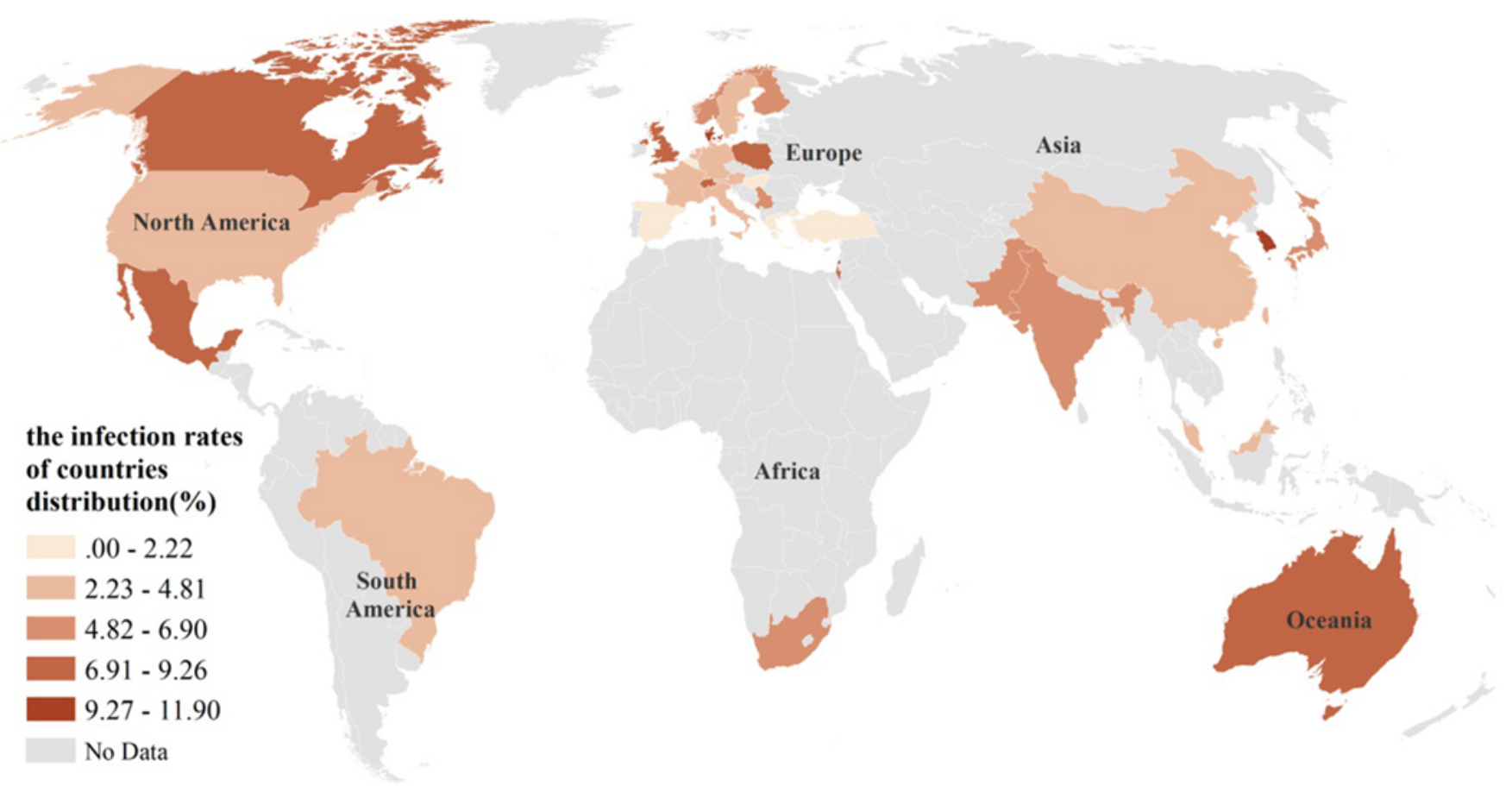

FIG. 4. Map of the distribution of IRs by country.

advantages, cranioplasty has recently become more common in neurosurgical practice. The IR of cranioplasty will hopefully decrease as surgeons' experience and awareness of infection prevention and control gradually increase.

The IRs of implants and equipment, however, are still high in the application of these neurosurgical procedures. In addition, infection remains a core concern with regard to implant failure and patient health. ${ }^{39,68}$ There are many causative factors that can impact the infection risk for a patient, such as preexisting infections, the latency period between tissue removal and implant insertion, ${ }^{39,46}$ and operating time. ${ }^{68,85}$ Neurosurgical implants include fixation devices for craniotomy, synthetic cranioplasties, various polymers, metal or ceramic materials, internal shunt systems, external ventricular drains, and neurostimulators. ${ }^{51}$ When comparing the IRs of different implants, it is essential to recognize differences such as material properties, biocompatibility, and bioactivity. Autologous bone is not subject to immune rejection and is effective as a substrate for bone ingrowth and revascularization. ${ }^{7,38} \mathrm{Khan}$ et al. stated that the IRs of autologous bone varied between

\section{TABLE 4. IRs categorized by time periods}

\begin{tabular}{cccc}
\hline Years & Total & Infection & IR $(\%)$ \\
\hline $1978-1987$ & 1025 & 39 & 3.80 \\
\hline $1988-1997$ & 3108 & 127 & 4.09 \\
\hline $1998-2007$ & 6420 & 236 & 3.68 \\
\hline $2008-2018$ & 12,413 & 714 & 5.75 \\
\hline Total & 22,966 & 1116 & 4.86 \\
\hline
\end{tabular}

Because only 1 article from the period 1968-1977 met the criteria, it was not included in the table.
$5.93 \%$ and $25 \%$, with an average IR of $10.50 \%,{ }^{45}$ which was in line with our studies (IR 6.58\%). Lee et al. reported that autologous implants had significantly more reoperations than synthetic implants, ${ }^{54}$ which could impact the effectiveness of potential vascularization and reintegration, ${ }^{31,91}$ resulting in the autologous bone being shielded from the immune system and therefore presenting an ideal scaffold for bacteria, as well as a risk of implant failure, donor-site morbidity, increased operating time, insufficient autogenous grafts, and difficulty in contouring the bone to fit the defects. ${ }^{16,73,90,91,94}$ However, Yadla et al. conducted a systematic review of 14 retrospective studies published between 1966 and 2010 and found no difference in IRs of autograft and allograft materials. ${ }^{94}$

Titanium is a versatile metal and is used in a number of different structural forms in the field of cranioplasty. Forms of titanium used in neurosurgical procedures can be further split into titanium mesh and titanium plates. ${ }^{51}$ Titanium implants often require prefabrication,,${ }^{18,25}$ leading to an increased lead time and cost, and intraoperative alteration remains difficult. ${ }^{4}$ In this study, the number of titanium implants was 810 , with an average IR of $8.15 \%$, which should cause the clinician to be cautious with their use.

Resorbable bone implant systems were developed in the 1990s and have gained wide use in pediatric cranial and facial surgery. ${ }^{3,23}$ The absorbable plating systems do not erode bone when placed in children..$^{19}$ Commercially resorbable plating systems are composed of polyglycolic and polylactic acids, and are fabricated into various plates, meshes, buttons, screws, tacks, or pins. ${ }^{23}$ In the past few decades, resorbable materials have been the most common neurosurgical procedures, with 2897 patients included in this meta-analysis, but only 26 cases of infection were re- 
ported and the overall IR was $0.90 \%$; this outcome was consistent with the earlier reviews. ${ }^{3,29,74}$ Hence, we should take these implants into account in pediatric cranial and facial surgery, considering IRs in combination with the advantages of these implants.

This study was designed to provide the highest-quality data available to detail common pathogenic microorganisms of neurosurgical practice in the past decades. According to our inclusion criteria, all bacteriological cultures should be performed using standard laboratory procedures. The main causative pathogen is $S$. aureus, including methicillin-resistant $S$. aureus (MRSA) and methicillin-sensitive $S$. aureus (MSSA), which is consistent with other published reports. ${ }^{2,30,43,61,67,72,77}$ Given the frequency of $S$. aureus infections and their severity, the regimen selected should be aimed at these pathogenic microorganisms. Furthermore, operative technique also plays an important role in preventing postoperative infections. ${ }^{27}$ Also, timing seems to be significant in avoiding complications in the neurological outcome of patients. ${ }^{94}$ To reduce the risk of infections as complications, it is generally recommended that patients wait at least 3 months after the injury before repair of a bony deficit is attempted..$^{58}$ If the conservative treatment does not promptly improve the clinical condition of a patient, a deep incisional infection should be considered and removal of the biomaterial followed by long-term antibiotic therapy is suggested. ${ }^{2}$ To our knowledge, vancomycin used in perioperative prophylaxis significantly reduces the risk of $S$. aureus surgical site infections (SSIs). Abode-Iyamah et al. assessed the use of intrawound vancomycin powder after cranioplasty and whether it would reduce the number of SSIs caused by common skin flora-theirs was the first study to evaluate the efficacy of intrawound vancomycin powder for preventing SSI after cranioplasty. ${ }^{2}$ Their study did not find that intrawound vancomycin powder reduced the SSI rate. In contrast, Abdullah et al. reported that the IR among patients who did not receive vancomycin powder during craniotomy procedures was significantly higher $(6.7 \%)$ than that for patients who did receive vancomycin powder $(1.3 \%) .{ }^{1}$ Most studies found that this practice was associated with decreased SSI rates after spine operations. ${ }^{54,69,86,88}$ Thus, sufficient data should be investigated in future studies and effective methods can be identified for decreasing the risk of SSI after cranioplasty.

Many studies still lack pooled data on the IRs from all over the world and their changes over a period of multiple decades. In our subgroup analysis, the IR in the US was less than the total worldwide IR. This may be related to the fact that the US is a developed country that has a sound healthcare system and a more mature technique regarding neurosurgery. In China, the overall IR is slightly above the total worldwide IR. These studies were mainly published in Taiwan, Guangdong, and Beijing-therefore, these data can only be used as a reference; the actual IR may be higher than our statistical data, and this phenomenon may be influenced by the antibiotic resistance of bacteria in China.

In this study, we found that except for the low IR from 1998 to 2007, the overall implant IRs after neurosurgical procedures were on the rise. We reanalyzed the literature published between 1998 and 2007 and found that of the 49 studies, only 14 articles from Asia and Africa were selected, among which 7 articles were published by researchers in Japan, 3 in India, and 1 in China. However, from 2008 to 2018, a total of 118 papers were counted, 30 of which were published in Asia and Africa, among which 14 articles were published by researchers in China. It can be seen that the IR of Asian and African countries was low from 1998 to 2007 due to the limited articles related to implant infection after neurosurgical procedures. However, due to the large number of articles published from 2008 to 2018 , the implant IR after neurosurgical procedures had a certain referential meaning.

Our meta-analysis had some limitations. First, one limitation of our analysis is that some patients were not contacted personally after hospitalization or finally died of other nonneurosurgical diseases, so some infections may have been missed. However, the type and proportion of infections are roughly the same as the statistical results. Second, available studies consisted of published data-unpublished data were not identified. This suggests that publication bias cannot be absolutely excluded even though no significant publication bias was observed. ${ }^{51}$ It was impossible to completely exclude the influence of confounding factors inherent in these included studies, although subgroup analyses by population, sex, region, periods of time, and study design were performed. Third, the other limitation is that our analysis was based on data obtained from retrospective articles, which possibly makes it difficult to avoid and assess bias.

\section{Conclusions}

In this meta-analysis of 227 studies with 1118 patients who experienced infections, the total IR was $4.87 \%$, which was more severe in neurosurgical procedures. The IRs of polypropylene-polyester, titanium, and PEEK implants were higher, which means that more attention should be paid to these materials. However, the IRs of Medpor porous polyethylene, biodegradable or resorbable devices, and dura mater were lower than $1.00 \%$, so surgeons could also think about using these implanted materials in appropriate neurosurgical procedures. In addition, the most common organisms involved in implant infections after neurosurgical procedures were gram-positive organisms, such as S. aureus, coagulase-negative Staphylococcus, and $P$. acnes, which can provide a certain reference for the clinic.

\section{Acknowledgments}

Funding information: this work was supported by grants from the National Natural Science Foundation of China (81702103), Jiangsu Provincial Natural Science Foundation (BK20170252), Projects for Jiangsu Provincial Young Medical Talents (QNRC2016780), General Program of the Natural Science Foundation of the Jiangsu Higher Education Institutions of China (16KJD320005), and Xuzhou Science and Technology Planning Project (KC16SY157).

\section{References}

1. Abdullah KG, Attiah MA, Olsen AS, Richardson A, Lucas TH: Reducing surgical site infections following craniotomy: 
examination of the use of topical vancomycin. J Neurosurg 123:1600-1604, 2015

2. Abode-Iyamah KO, Chiang HY, Winslow N, Park B, Zanaty $\mathrm{M}$, Dlouhy BJ, et al: Risk factors for surgical site infections and assessment of vancomycin powder as a preventive measure in patients undergoing first-time cranioplasty. J Neurosurg 128:1241-1249, 2018

3. Ahmad N, Lyles J, Panchal J, Deschamps-Braly J: Outcomes and complications based on experience with resorbable plates in pediatric craniosynostosis patients. J Craniofac Surg 19:855-860, 2008 (Erratum in J Craniofac Surg 21:613, 2010)

4. Aldana PR, Roy S, Postlethwait RA, James HE: Ultrasoundaided fixation of a biodegradable cranial fixation system: uses in pediatric neurosurgery. J Neurosurg Pediatr 3:420-424, 2009

5. Antes S, Tschan CA, Kunze G, Ewert L, Zimmer A, Halfmann A, et al: Clinical and radiological findings in long-term intracranial pressure monitoring. Acta Neurochir (Wien) 156:1009-1019, 2014

6. Archavlis E, Carvi Y Nievas M: The impact of timing of cranioplasty in patients with large cranial defects after decompressive hemicraniectomy. Acta Neurochir (Wien) 154:1055-1062, 2012

7. Aydin S, Kucukyuruk B, Abuzayed B, Aydin S, Sanus GZ: Cranioplasty: review of materials and techniques. J Neurosci Rural Pract 2:162-167, 2011

8. Beuriat PA, Szathmari A, Grassiot B, Di Rocco F, Mottolese C: [Why a hydroxyapatite cranioplasty can be used to repair a cranial bone defect in children: experience of 19 cases.] Neurochirurgie 62:251-257, 2016 (French)

9. Blond S, Siegfried J: Thalamic stimulation for the treatment of tremor and other movement disorders. Acta Neurochir Suppl (Wien) 52:109-111, 1991

10. Bonda DJ, Manjila S, Selman WR, Dean D: The recent revolution in the design and manufacture of cranial implants: modern advancements and future directions. Neurosurgery 77:814-824, 2015

11. Brandicourt P, Delanoé F, Roux FE, Jalbert F, Brauge D, Lauwers F: Reconstruction of cranial vault defect with polyetheretherketone implants. World Neurosurg 105:783-789, 2017

12. Brommeland T, Rydning PN, Pripp AH, Helseth E: Cranioplasty complications and risk factors associated with bone flap resorption. Scand J Trauma Resusc Emerg Med 23:75, 2015

13. Buffet-Bataillon S, Haegelen C, Riffaud L, Bonnaure-Mallet M, Brassier G, Cormier M: Impact of surgical site infection surveillance in a neurosurgical unit. J Hosp Infect 77:352355, 2011

14. Carty MJ, Ferraro N, Upton J: Reconstruction of pediatric cranial base defects: a review of a single microsurgeon's 30 year experience. J Craniofac Surg 20 (Suppl 1):639-645, 2009

15. Cassir N, De La Rosa S, Melot A, Touta A, Troude L, Loundou A, et al: Risk factors for surgical site infections after neurosurgery: a focus on the postoperative period. Am J Infect Control 43:1288-1291, 2015

16. Cheng CH, Lee HC, Chen CC, Cho DY, Lin HL: Cryopreservation versus subcutaneous preservation of autologous bone flaps for cranioplasty: comparison of the surgical site infection and bone resorption rates. Clin Neurol Neurosurg 124:85-89, 2014

17. Chiang HY, Steelman VM, Pottinger JM, Schlueter AJ, Diekema DJ, Greenlee JD et al: Clinical significance of positive cranial bone flap cultures and associated risk of surgical site infection after craniotomies or craniectomies. J Neurosurg 114:1746-1754, 2011

18. Chim H, Schantz JT: New frontiers in calvarial reconstruction: integrating computer-assisted design and tissue engi- neering in cranioplasty. Plast Reconstr Surg 116:1726-1741, 2005

19. Cohen SR, Holmes RE, Amis P, Fitchner H, Shusterman EM: Tacks: a new technique for craniofacial fixation. J Craniofac Surg 12:596-602, 2001

20. Courtemanche AD, Thompson GB: Silastic cranioplasty following cranio-facial injuries. Plast Reconstr Surg 41:165170, 1968

21. Davis R, Kudzman J, Ratzan K: Management of infected cerebellar stimulation systems. Neurosurgery 10:340-343, 1982

22. Di Rocco C, Marchese E, Velardi F: A survey of the first complication of newly implanted CSF shunt devices for the treatment of nontumoral hydrocephalus. Cooperative survey of the 1991-1992 Education Committee of the ISPN. Childs Nerv Syst 10:321-327, 1994

23. Eppley BL, Morales L, Wood R, Pensler J, Goldstein J, Havlik RJ, et al: Resorbable PLLA-PGA plate and screw fixation in pediatric craniofacial surgery: clinical experience in 1883 patients. Plast Reconstr Surg 114:850-857, 2004

24. Ernst G, Qeadan F, Carlson AP: Subcutaneous bone flap storage after emergency craniectomy: cost-effectiveness and rate of resorption. J Neurosurg 129:1604-1610, 2018

25. Eufinger H, Rasche C, Wehmöller M, Schmieder K, Scholz $\mathrm{M}$, Weihe $\mathrm{S}$, et al: CAD/CAM titanium implants for cranioplasty-an evaluation of success and quality of life of 169 consecutive implants with regard to size and location. Int Congr Ser 1281:827-831, 2005

26. Eufinger H, Saylor B: Computer-assisted prefabrication of individual craniofacial implants. AORN J 74:648-656, 658-662, 2001

27. Falowski SM, DiLorenzo DJ, Shannon LR, Wallace DJ, Devries J, Kellogg RG, et al: Optimizations and nuances in neurosurgical technique for the minimization of complications in subdural electrode placement for epilepsy surgery. World Neurosurg 84:989-997, 2015

28. Fan WT, Qin TT, Bi RR, Kang HQ, Ma P, Gu B: Performance of the matrix-assisted laser desorption ionization time-offlight mass spectrometry system for rapid identification of streptococci: a review. Eur J Clin Microbiol Infect Dis 36:1005-1012, 2017

29. Freudlsperger C, Castrillon-Oberndorfer G, Baechli H, Hoffmann J, Mertens C, Engel M: The value of ultrasoundassisted pinned resorbable osteosynthesis for cranial vault remodelling in craniosynostosis. J Craniomaxillofac Surg 42:503-507, 2014

30. Goh RC, Chang CN, Lin CL, Lo LJ: Customised fabricated implants after previous failed cranioplasty. J Plast Reconstr Aesthet Surg 63:1479-1484, 2010

31. Goldstein JA, Paliga JT, Bartlett SP: Cranioplasty: indications and advances. Curr Opin Otolaryngol Head Neck Surg 21:400-409, 2013

32. Gorgulho A, Juillard C, Uslan DZ, Tajik K, Aurasteh P, Behnke E, et al: Infection following deep brain stimulator implantation performed in the conventional versus magnetic resonance imaging-equipped operating room. J Neurosurg 110:239-246, 2009

33. Gu B, Ke X, Pan S, Cao Y, Zhuang L, Yu R, et al: Prevalence and trends of aminoglycoside resistance in Shigella worldwide, 1999-2010. J Biomed Res 27:103-115, 2013

34. Hersh EH, Virk MS, Shao H, Tsiouris AJ, Bonci GA, Schwartz TH: Bone flap explantation, steroid use, and rates of infection in patients with epilepsy undergoing craniotomy for implantation of subdural electrodes. J Neurosurg 119:48-53, 2013

35. Hill CS, Luoma AM, Wilson SR, Kitchen N: Titanium cranioplasty and the prediction of complications. Br J Neurosurg 26:832-837, 2012

36. Honeybul S, Janzen C, Kruger K, Ho KM: The impact of 
cranioplasty on neurological function. Br J Neurosurg 27:636-641, 2013

37. Huang YH, Lee TC, Yang KY, Liao CC: Is timing of cranioplasty following posttraumatic craniectomy related to neurological outcome? Int J Surg 11:886-890, 2013

38. Iaccarino CR, Ghadipour R, Carinci F, Servadei F: Porous hydroxyapatite custom made cranioplasty: the 3D design techniques prostheses in 21 patients. J Osteol Biomater 2:43-53, 2011

39. Im SH, Jang DK, Han YM, Kim JT, Chung DS, Park YS: Long-term incidence and predicting factors of cranioplasty infection after decompressive craniectomy. J Korean Neurosurg Soc 52:396-403, 2012

40. Janzen C, Kruger K, Honeybul S: Syndrome of the trephined following bifrontal decompressive craniectomy: implications for rehabilitation. Brain Inj 26:101-105, 2012

41. Joffe J, Harris M, Kahugu F, Nicoll S, Linney A, Richards $\mathrm{R}$ : A prospective study of computer-aided design and manufacture of titanium plate for cranioplasty and its clinical outcome. Br J Neurosurg 13:576-580, 1999

42. Jonkergouw J, van de Vijfeijken SE, Nout E, Theys T, Van de Casteele E, Folkersma H, et al: Outcome in patient-specific PEEK cranioplasty: a two-center cohort study of 40 implants. J Craniomaxillofac Surg 44:1266-1272, 2016

43. Kaminska M, Perides S, Lumsden DE, Nakou V, Selway R, Ashkan K, et al: Complications of deep brain stimulation (DBS) for dystonia in children-the challenges and 10 year experience in a large paediatric cohort. Eur J Paediatr Neurol 21:168-175, 2017

44. Keen JR, Przekop A, Olaya JE, Zouros A, Hsu FP: Deep brain stimulation for the treatment of childhood dystonic cerebral palsy. J Neurosurg Pediatr 14:585-593, 2014

45. Khan NR, Thompson CJ, DeCuypere M, Angotti JM, Kalobwe E, Muhlbauer MS, et al: A meta-analysis of spinal surgical site infection and vancomycin powder. J Neurosurg Spine 21:974-983, 2014

46. Kim BJ, Hong KS, Park KJ, Park DH, Chung YG, Kang SH: Customized cranioplasty implants using three-dimensional printers and polymethyl-methacrylate casting. J Korean Neurosurg Soc 52:541-546, 2012

47. Klinger DR, Madden C, Beshay J, White J, Gambrell K, Rickert K: Autologous and acrylic cranioplasty: a review of 10 years and 258 cases. World Neurosurg 82:e525-e530, 2014

48. Kotwica Z, Zawirski M, Andrzejak S, Papierz W, Chmielowski M: Cranioplasty of an extremely large cranial defect caused by transitional meningioma with a knitted polypropylen-polyester prothesis "Codubix". Acta Neurochir (Wien) 112:147-150, 1991

49. Kourbeti IS, Vakis AF, Papadakis JA, Karabetsos DA, Bertsias G, Filippou M, et al: Infections in traumatic brain injury patients. Clin Microbiol Infect 18:359-364, 2012

50. Kung WM, Lin MS: A simplified technique for polymethyl methacrylate cranioplasty: combined cotton stacking and finger fracture method. Brain Inj 26:1737-1742, 2012

51. Kwarcinski J, Boughton P, Ruys A, Doolan A, van Gelder $\mathrm{J}$ : Cranioplasty and craniofacial reconstruction: a review of implant material, manufacturing method and infection risk. Appl Sci (Basel) 7:276, 2017

52. Lee CH, Chung YS, Lee SH, Yang HJ, Son YJ: Analysis of the factors influencing bone graft infection after cranioplasty. J Trauma Acute Care Surg 73:255-260, 2012

53. Lee JC, Kleiber GM, Pelletier AT, Reid RR, Gottlieb LJ: Autologous immediate cranioplasty with vascularized bone in high-risk composite cranial defects. Plast Reconstr Surg 132:967-975, 2013

54. Lee SH, Yoo CJ, Lee U, Park CW, Lee SG, Kim WK: Resorption of autogenous bone graft in cranioplasty: resorption and reintegration failure. Korean J Neurotrauma 10:10-14, 2014
55. Lethaus B, Safi Y, ter Laak-Poort M, Kloss-Brandstätter A, Banki F, Robbenmenke C, et al: Cranioplasty with customized titanium and PEEK implants in a mechanical stress model. J Neurotrauma 29:1077-1083, 2012

56. Lietard C, Thébaud V, Besson G, Lejeune B: Risk factors for neurosurgical site infections: an 18-month prospective survey. J Neurosurg 109:729-734, 2008

57. Liu C, Chen Z, Li T, Yang Z, Zhang Q, Yin J, et al: Effectiveness and safety of fire-needle moxibustion on insomnia: protocol for a systematic review and meta-analysis. Medicine (Baltimore) 98:e14509, 2019

58. Lopez J, Zhong SS, Sankey EW, Swanson EW, Susarla H, Jusue-Torres I, et al: Time interval reduction for delayed implant-based cranioplasty reconstruction in the setting of previous bone flap osteomyelitis. Plast Reconstr Surg 137:394e-404e, 2016

59. Ma IT, Symon MR, Bristol RE, Beals SP, Joganic EF, Adelson PD, et al: Outcomes of titanium mesh cranioplasty in pediatric patients. J Craniofac Surg 29:99-104, 2018

60. Machado M, Salcman M, Kaplan RS, Montgomery E: Expanded role of the cerebrospinal fluid reservoir in neurooncology: indications, causes of revision, and complications. Neurosurgery 17:600-603,1985

61. Malcolm JG, Mahmooth Z, Rindler RS, Allen JW, Grossberg JA, Pradilla G, et al: Autologous cranioplasty is associated with increased reoperation rate: a systematic review and meta-analysis. World Neurosurg 116:60-68, 2018

62. Malcolm JG, Rindler RS, Chu JK, Chokshi F, Grossberg JA, Pradilla G, et al: Early cranioplasty is associated with greater neurological improvement: a systematic review and metaanalysis. Neurosurgery 82:278-288, 2018

63. Marbacher S, Andereggen L, Erhardt S, Fathi AR, Fandino $\mathrm{J}$, Raabe A, et al: Intraoperative template-molded bone flap reconstruction for patient specific cranioplasty. Neurosurg $\operatorname{Rev} 35: 527-535,2012$

64. Marlier B, Kleiber JC, Bannwarth M, Theret E, Eap C, Litre $\mathrm{CF}$ : Reconstruction of cranioplasty using medpor porouspolyethylene implant. Neurochirurgie 63:468-472, 2017

65. McGovern PC, Lautenbach E, Brennan PJ, Lustig RA, Fishman NO: Risk factors for postcraniotomy surgical site infection after 1,3-bis (2-chloroethyl)-1-nitrosourea (Gliadel) wafer placement. Clin Infect Dis 36:759-765, 2003

66. Moazzam AA, Nehrer E, Da Silva SL, Polido JC, Arakelyan A, Habibian M, et al: The association between dental health and procedures and developing shunt infections in pediatric patients. J Neurosurg Pediatr 14:508-513, 2014

67. Morton RP, Abecassis IJ, Hanson JF, Barber J, Nerva JD, Emerson SN, et al: Predictors of infection after 754 cranioplasty operations and the value of intraoperative cultures for cryopreserved bone flaps. J Neurosurg 125:766-770, 2016

68. Mundinger GS, Latham K, Friedrich J, Louie O, Said H, Birgfeld C, et al: Management of the repeatedly failed cranioplasty following large postdecompressive craniectomy: establishing the efficacy of staged free latissimus dorsi transfer/tissue expansion/custom polyetheretherketone implant reconstruction. J Craniofac Surg 27:1971-1977, 2016

69. O'Neill KR, Smith JG, Abtahi AM, Archer KR, Spengler DM, McGirt MJ, et al: Reduced surgical site infections in patients undergoing posterior spinal stabilization of traumatic injuries using vancomycin powder. Spine J 11:641-646, 2011

70. O'Reilly EB, Barnett S, Madden C, Welch B, Mickey B, Rozen S: Computed-tomography modeled polyether ether ketone (PEEK) implants in revision cranioplasty. J Plast Reconstr Aesthet Surg 68:329-338, 2015

71. Park EK, Lim JY, Yun IS, Kim JS, Woo SH, Kim DS, et al: Cranioplasty enhanced by three-dimensional printing: custom-made three-dimensional-printed titanium implants for skull defects. J Craniofac Surg 27:943-949, 2016

72. Pepper J, Zrinzo L, Mirza B, Foltynie T, Limousin P, Hariz 
M: The risk of hardware infection in deep brain stimulation surgery is greater at impulse generator replacement than at the primary procedure. Stereotact Funct Neurosurg 91:5665,2013

73. Piitulainen JM, Kauko T, Aitasalo KM, Vuorinen V, Vallittu PK, Posti JP: Outcomes of cranioplasty with synthetic materials and autologous bone grafts. World Neurosurg 83:708-714, 2015

74. Piitulainen JM, Posti JP, Aitasalo KM, Vuorinen V, Vallittu PK, Serlo W: Paediatric cranial defect reconstruction using bioactive fibre-reinforced composite implant: early outcomes. Acta Neurochir (Wien) 157:681-687, 2015

75. Pople IK, Griffith HB: Control of hydrocephalus by endoscopic choroid plexus coagulation-long-term results and complications. Eur J Pediatr Surg 1:17-18, 1993

76. Reddy S, Khalifian S, Flores JM, Bellamy J, Manson PN, Rodriguez ED, et al: Clinical outcomes in cranioplasty: risk factors and choice of reconstructive material. Plast Reconstr Surg 133:864-873, 2014

77. Rosenthal G, Ng I, Moscovici S, Lee KK, Lay T, Martin C, et al: Polyetheretherketone implants for the repair of large cranial defects: a 3-center experience. Neurosurgery 75:523529,2014

78. Sahoo N, Roy ID, Desai AP, Gupta V: Comparative evaluation of autogenous calvarial bone graft and alloplastic materials for secondary reconstruction of cranial defects. J Craniofac Surg 21:79-82, 2010

79. Schoekler B, Trummer M: Prediction parameters of bone flap resorption following cranioplasty with autologous bone. Clin Neurol Neurosurg 120:64-67, 2014

80. Shah AM, Jung H, Skirboll S: Materials used in cranioplasty: a history and analysis. Neurosurg Focus 36(4):E19, 2014

81. Shapiro SA: Cranioplasty, vertebral body replacement, and spinal fusion with tobramycin-impregnated methylmethacrylate. Neurosurgery 28:789-791, 1991

82. Sneh-Arbib O, Shiferstein A, Dagan N, Fein S, Telem L, Muchtar E, et al: Surgical site infections following craniotomy focusing on possible post-operative acquisition of infection: prospective cohort study. Eur J Clin Microbiol Infect Dis 32:1511-1516, 2013

83. Song J, Liu M, Mo X, Du H, Huang H, Xu GZ: Beneficial impact of early cranioplasty in patients with decompressive craniectomy: evidence from transcranial Doppler ultrasonography. Acta Neurochir (Wien) 156:193-198, 2014

84. Staffa G, Nataloni A, Compagnone C, Servadei F: Custom made cranioplasty prostheses in porous hydroxy-apatite using 3D design techniques: 7 years experience in 25 patients. Acta Neurochir (Wien) 149:161-170, 2007

85. Strahm C, Albrich WC, Zdravkovic V, Schöbi B, Hildebrandt G, Schlegel M: Infection rate after cranial neurosurgical procedures: a prospective single-center study. World Neurosurg 111:e277-e285, 2018

86. Sweet FA, Roh M, Sliva C: Intrawound application of vancomycin for prophylaxis in instrumented thoracolumbar fusions: efficacy, drug levels, and patient outcomes. Spine (Phila Pa 1976) 36:2084-2088, 2011
87. Tokoro K, Chiba Y, Tsubone K: Late infection after cranioplasty-review of 14 cases. Neurol Med Chir 29:196-201, 1989

88. Tubaki VR, Rajasekaran S, Shetty AP: Effects of using intravenous antibiotic only versus local intrawound vancomycin antibiotic powder application in addition to intravenous antibiotics on postoperative infection in spine surgery in 907 patients. Spine (Phila Pa 1976) 38:2149-2155, 2013

89. Volsky PG, Hillman TA, Stromberg KJ, Buchinsky FJ, Chen DA, Jackson NM, et al: Hydroxyapatite cement cranioplasty following translabyrinthine approach: long-term study of 369 cases. Laryngoscope 127:2120-2125, 2017

90. Walcott BP, Kwon CS, Sheth SA, Fehnel CR, Koffie RM, Asaad WF, et al: Predictors of cranioplasty complications in stroke and trauma patients. J Neurosurg 118:757-762, 2013

91. Wiggins A, Austerberry R, Morrison D, Ho KM, Honeybul $\mathrm{S}$ : Cranioplasty with custom-made titanium plates -14 years experience. Neurosurgery 72:248-256, 2013

92. Williams LR, Fan KF, Bentley RP: Custom-made titanium cranioplasty: early and late complications of 151 cranioplasties and review of the literature. Int J Oral Maxillofac Surg 44:599-608, 2015

93. Wurm G, Tomancok B, Holl K, Trenkler J: Prospective study on cranioplasty with individual carbon fiber reinforced polymere (CFRP) implants produced by means of stereolithography. Surg Neurol 62:510-521, 2004

94. Yadla S, Campbell PG, Chitale R, Maltenfort MG, Jabbour P, Sharan AD: Effect of early surgery, material, and method of flap preservation on cranioplasty infections: a systematic review. Neurosurgery 68:1124-1130, 2011

95. Zanaty M, Chalouhi N, Starke RM, Clark SW, Bovenzi CD, Saigh M, et al: Complications following cranioplasty: incidence and predictors in 348 cases. J Neurosurg 123:182188,2015

\section{Disclosures}

The authors report no conflict of interest concerning the materials or methods used in this study or the findings specified in this paper.

\section{Author Contributions}

Conception and design: Gu. Acquisition of data: Zhang, Qin. Analysis and interpretation of data: Zhang. Drafting the article: Zhang. Critically revising the article: Chen. Reviewed submitted version of manuscript: Gu. Statistical analysis: Qin, Wang, Li. Administrative/technical/material support: Chen. Study supervision: Gu, Wang, Li.

\section{Correspondence}

Bing Gu: Xuzhou Medical University, Xuzhou, China. gb20031129@163.com. 